\title{
Effects of different methionine sources on production and reproduction performance, egg quality and serum biochemical indices of broiler breeders
}

\author{
Xue Xiao ${ }^{1}$, Yongxia Wang ${ }^{2}$, Weilong Liu $^{3}$, Tingting Ju ${ }^{1}$, and Xiuan Zhan ${ }^{1, *}$
}

\footnotetext{
* Corresponding Author: Xiuan Zhan Tel: +86-571-88982127, Fax: +86-571-88982650, E-mail: xazan@zju.edu.cn

'Feed Science Institute, College of Animal Science, Zhejiang University, Hangzhou, Zhejiang 310058, China

${ }^{2}$ College of Animal Science and Technology, Zhejiang Agricultural and Forestry University, Lin'an, Zhejiang 311300, China

${ }^{3}$ Animal Husbandry and Veterinary Bureau, Tongxiang, Zhejiang 314500, China
}

Submitted May 21, 2016; Revised Sept 2, 2016; Accepted Dec 7, 2016
Objective: The study was conducted to evaluate the effects of different methionine (Met) sources on production performance, reproduction performance, egg quality and serum biochemical indices in broiler breeders.

Methods: After receiving a basal diet (containing 0.25\% Met) for a 2-wk pretreatment period, a total of 360 39-wk-old Lingnan yellow broiler breeders were randomly allocated to four treatments with six replicates each (15 birds per replicate). Breeders were fed with basal diets (control) or diets supplemented with DL-methionine (DLM), DL-2-hydroxy-4-methylthio butytric calcium (MHA-Ca) and coated DL-Met (CME) respectively.

Results: The results showed that CME supplementation promoted laying rate and decreased feed-to-egg ratio $(\mathrm{F} / \mathrm{E})(\mathrm{p}<0.05), \mathrm{DLM}$ and MHA-Ca supplementation decreased $\mathrm{F} / \mathrm{E}(\mathrm{p}<0.05)$ when compared with control group. The rate of fertility, hatchability and birthrate were higher $(\mathrm{p}<0.05)$ in DLM, MHA-Ca, and CME groups than control group. Compared with control group, CME increased the eggshell thickness ( $\mathrm{p}<0.05)$; MHA-Ca improved the eggshell thickness, shell ratio and eggshell strength $(\mathrm{p}<0.05)$. Results also showed that $\mathrm{CME}$ elevated the concentration of total protein in serum $(\mathrm{p}<0.05)$; MHA-Ca improved the concentration of calcium in serum $(\mathrm{p}<0.05)$. The concentration of serum uric acid in DLM, MHA-Ca, and CME groups was lower than that in control group $(\mathrm{p}<0.05)$. Besides, CME had higher concentrations of serum taurine, cysteine and cystanthionine $(\mathrm{p}<0.05)$ while MHA-Ca and DLM promoted the serum taurine concentration $(\mathrm{p}<0.05)$ compared with control group.

Conclusion: Based on the results, it was concluded that Met supplementation could enhance the production and reproduction performance as well as the antioxidant status and egg quality of broiler breeders. In terms of improving the production performance, reproduction performance and antioxidant performance, CME was superior to DLM and MHA-Ca; but in regard to the enhancement of eggshell quality and serum Ca concentration, MHA-Ca was superior to DLM and CME.

Keywords: Broiler Breeder; Methionine; Production Performance; Reproduction Performance; Serum Biochemical Indices

\section{INTRODUCTION}

Methionine (Met) plays critical roles in methylation reaction, protein accretion [1], growth performance promotion [2,3] and immune responses enhancement [4]. It is generally considered to be the first limiting amino acid in poultry diets. DL-Met powder (DLM) and DL-2-hydroxy4-methylthio butanoic acid (MHA) are two major Met sources generally used in feed industry [5]. In recent years, coated DL-Met (CME) has been applied in animal feed because of the high utilization of Met, especially in aquaculture industry [6].

The MHA resembles Met in chemical structure, with a hydroxyl group instead of an amino 
group, and it can be equimolar transformed to Met by transamination. Previous studies showed that MHA was equally or less active than DLM in bioavailability $[7,8]$. However, MHA showed other advantages over DLM, such as lower nitrogen excretion and less toxicity of sulfur-containing amino acid [9]. MHA reacting with calcium carbonate produced DL-2-hydroxy-4-methylthio butytric calcium (MHA-Ca), which can be converted to MHA at an equimolar level. Van [10] reported that MHA-Ca performed higher promotion in egg production than MHA. Coated DL-Met is protected with natural materials which are difficult to degrade by microorganism and sensitive to the change of $\mathrm{pH}$, such as stearic acid, glyceride and gelatin. Those materials help DL-Met effectively to be used in protein synthesis by continuous release in digestive tract [11].

Dietary protein was used in the form of amino acids or small peptides in the process of digestion while free amino acids (FAA) added to the feed were directly absorbed, which leads to low protein synthesis because of the asynchronous absorption. Thus the slower release of FAA in the intestinal tract could give a better utilization. Coating the FAA with a digestion-resistant compound is a good solution. Chi et al [6] reported that compared with the crystalline Met, CME had higher utilization because of the reduced release rate in the intestinal tract. However, no attention has been paid to comparing the effects of DLM, MHA-Ca, and $\mathrm{CME}$ on broiler breeders. Thus, the objective of this study was to investigate the effects of different Met sources on production performance, reproduction performance, egg quality and serum biochemical indices in broiler breeders.

\section{MATERIALS AND METHODS}

\section{General}

This project was approved by the Institution Animal Care and Use Committee at Zhejiang University, and the animal trial was conducted in accordance with the National Institutes of Health Guidelines for the care and use of laboratory animals. DLM was obtained from Evonik (99\% pure, Evonik Degussa Co, Dusseldorf, Germany), MHA-Ca was purchased from Novous (containing $84 \%$ active substance, Novous Chemical Co, St. Charles City, MO, USA), CME was obtained from King Techina (containing $40 \%$ of active substance, King Techina Co, Hangzhou, China).

\section{Experimental design and treatments}

A total of 360 39-wk-old Lingnan yellow broiler breeders were randomly distributed into four treatments, each of which contained six replicates with 15 birds per replicate. After a 2-wk pretreatment receiving a basal diet shown in Table 1, an 8-wk experiment was conducted. The treatment groups were as follows: i) control group: basal diet, ii) DLM group: basal diet+DLM, iii) MHA-Ca group: basal diet+MHA-Ca, iv) CME group: basal diet+CME. All the Met sources were supplemented in basal diets with an equimolar Met basis, containing $0.1 \%$ Met for each experi-
Table 1. Composition and nutrient levels of the basal diets $(\mathrm{g} / \mathrm{kg}$, unless otherwise stated)

\begin{tabular}{lc}
\hline Items & \\
\hline Ingredients (\%) & 64.0 \\
$\quad$ Corn grain & 26.0 \\
Soybean meal & 5.2 \\
Limestone & 1.0 \\
CaHPO4 & 0.3 \\
NaCl & 2.5 \\
Shell power & 1.0 \\
Premix ${ }^{1)}$ & 100 \\
Total & \\
Nutrient levels (\%) & 11.24 \\
ME') (MJ/kg) & 15.92 \\
Crude protein & 3.03 \\
Calcium & 0.50 \\
Total phosphorus & 0.83 \\
Lysine & 0.25 \\
Methionine & 0.53 \\
Methionine+cysteine & 0.62 \\
Threonine &
\end{tabular}

$\mathrm{ME}$, metabolizable energy.

1) Supplied the following per kilogram of diet: iron, $80 \mathrm{mg}$; copper, $8 \mathrm{mg}$; zinc, $80 \mathrm{mg}$; manganese, $100 \mathrm{mg}$; iodine, $1 \mathrm{mg}$; selenium, $0.3 \mathrm{mg}$, vitamin $A, 10,800 \mathrm{IU}$; vitamin $\mathrm{D}_{3}$, 2,160 IU; vitamin $E_{2} 27 \mathrm{mg}$; vitamin $\mathrm{K}_{3}, 1.4 \mathrm{mg}$; vitamin $B_{1}, 1.8 \mathrm{mg}$; vitamin $\mathrm{B}_{2}, 8 \mathrm{mg}$; vitamin $B_{6}, 4.1 \mathrm{mg}$; vitamin $B_{12}, 0.01 \mathrm{mg}$; niacin, $32 \mathrm{mg}$; D-calcium pantothenate, 11 $\mathrm{mg}$; folic acid, $1.1 \mathrm{mg}$; biotin, $0.18 \mathrm{mg}$.

${ }^{2)} \mathrm{ME}$ was calculated from data provide by Feed Database in China [28].

mental group. During the trial period, feed was restricted. All birds were housed in cages with following dimensions (length $\times$ depth $\times$ front height $\times$ rear height): $35.5 \mathrm{~cm} \times 35.5 \mathrm{~cm} \times 43 \mathrm{~cm} \times 50 \mathrm{~cm}$ with two hens per cage where the temperature was maintained between $24^{\circ} \mathrm{C}$ and $30^{\circ} \mathrm{C}$. Hens were artificially inseminated weekly. Daily egg production records were kept and summarized per week. All eggs collected were stored in storage room where the temperature was between $10^{\circ} \mathrm{C}$ and $15^{\circ} \mathrm{C}$ and incubated once a week, during the incubation period, the number of no-fertilized eggs and dead sperm eggs were recorded to calculate fertility and hatchability of fertile eggs. The amount of live hatched was recorded for the calculation of birthrate. The weight of eggs was recorded daily, and the feed intake was recorded every week to calculate the feed-to-egg ratio $(\mathrm{F} / \mathrm{E})$.

\section{Sample collections and preparations}

At the end of the experiment, four breeders per replicate were randomly selected and punctured at the wing vein for blood samples with pro-coagulation tubes. Serum was separated by centrifuge at $4^{\circ} \mathrm{C}(3,000 \mathrm{rpm}, 10 \mathrm{~min})$, then stored at $-80^{\circ} \mathrm{C}$ for further biochemical analysis.

\section{Chemical analyses}

The concentrations of total protein (TP), uric acid (UA), calcium $(\mathrm{Ca})$, and total phosphorus $(\mathrm{P})$ in serum were determined by commercial kits (Nanjing Jiancheng Bio engineering Institute, 
Nanjing, China). All the procedures were carried out according to the instructions of the assay kits.

\section{Egg quality determination}

Egghell weights were determined by PL602-L analytical balance (Mettler Toledo Co, Zurich, Switzerland). Eggshell thickness, eggshell strength, albumen height and haugh unit were detected by DET 6,000 egg quality tester (NABEL Co., Ltd, Tokyo, Japan). The length and width, measured by vernier caliper, were recorded to calculate the egg shape index.

\section{Determination of Met metabolites}

One $\mathrm{mL} 2 \%$ 5-sulfo salicylic acid and $0.5 \mathrm{~mL} 2.0 \mathrm{mmol} / \mathrm{L}$ ethylenediaminetetraacetic acid were added into $1.0 \mathrm{~mL}$ serum samples and them mixed. One hour later, the mixture was centrifuged at $4,000 \mathrm{rpm}$ for $10 \mathrm{~min}$ at $4^{\circ} \mathrm{C}$, then $5 \mathrm{~mL} 0.02 \mathrm{~mol} / \mathrm{L} \mathrm{HCl}$ was added into $0.25 \mathrm{~mL}$ supernatant. The taurine, cysteine and cystathionine concentrations were determined with L-8900 automatic amino acid analyzer (Hitachi Ltd, Tokyo, Japan) after $0.22 \mu \mathrm{m}$ polyethylene membrane filtration.

\section{Statistical analysis}

All data were statistically analyzed by one-way analysis of variance procedure of SPSS 16.0 for Windows. Comparisons between groups were made by Duncan's multiple range test. Statistical significance for all data was considered to be $\mathrm{p}<0.05$. The data was presented as means \pm standard deviation.

\section{RESULTS}

\section{Production performance}

Effects of different Met sources on the production performance of broiler breeders are shown in Table 2. Compared with control group, CME significantly $(\mathrm{p}<0.05)$ improved the laying rate while DLM and MHA-Ca showed a trend of promotion ( $p>0.05)$. And $\mathrm{F} / \mathrm{E}$ was significantly $(\mathrm{p}<0.05)$ decreased in DLM, MHA-Ca, and CME groups compared with control group. No difference ( $p>0.05$ ) was observed among the four treatments on average egg weight.

\section{Reproduction performance}

Table 3 shows the effects of different Met sources on the reproduction performance of broiler breeders. The supplementation of DLM, MHA-Ca, and CME significantly $(\mathrm{p}<0.05)$ improved the fertility rate, hatching rate and birth rate compared with the control group.

\section{Egg quality indices}

Effects of different Met sources on egg quality are shown in Table 4. Compared with control group, MHA-Ca enhanced the eggshell thickness, relative eggshell weight and eggshell strength $(\mathrm{p}<0.05)$

Table 2. Effects of different methionine sources on production performance of broiler breeders

\begin{tabular}{lcccc}
\hline Items & Control & DLM & MHA-Ca & CME \\
\hline Laying rate (\%) & $50.86 \pm 2.68^{\mathrm{b}}$ & $54.52 \pm 1.69^{\mathrm{ab}}$ & $53.19 \pm 0.75^{\mathrm{ab}}$ & $55.70 \pm 1.9^{\mathrm{a}}$ \\
Average egg weight (g) & $53.92 \pm 0.64$ & $53.97 \pm 1.12$ & $54.05 \pm 1.25$ & $55.10 \pm 1.21$ \\
Feed-to-egg ration(F/E, g:g) & $4.63 \pm 0.28^{\mathrm{a}}$ & $4.24 \pm 0.13^{\mathrm{b}}$ & $4.30 \pm 0.10^{\mathrm{b}}$ & $4.29 \pm 0.23^{\mathrm{b}}$ \\
\hline
\end{tabular}

Control, basal diet; DLM, DL-methionine; MHA-Ca, DL-2-hydroxy-4-methylthio butytric calcium; CME, coated DL-methionine.

${ }^{a b}$ Different letters significantly different $(p<0.05)$.

Table 3. Effects of different methionine sources on reproduction performance of broiler breeders

\begin{tabular}{lcccc}
\hline Items & Control & DLM & MHA-Ca & CME \\
\hline Fertility rate (\%) & $84.11 \pm 2.94^{\mathrm{b}}$ & $91.08 \pm 2.88^{\mathrm{a}}$ & $90.91 \pm 0.70^{\mathrm{a}}$ & $92.09 \pm 1.65^{\mathrm{a}}$ \\
Hatching rate (\%) & $86.28 \pm 1.43^{\mathrm{b}}$ & $88.09 \pm 2.33^{\mathrm{a}}$ & $89.79 \pm 1.73^{\mathrm{a}}$ & $90.58 \pm 1.29^{\mathrm{a}}$ \\
Birth rate (\%) & $72.54 \pm 1.51^{\mathrm{b}}$ & $80.27 \pm 4.70^{\mathrm{a}}$ & $81.64 \pm 2.08^{\mathrm{a}}$ & $83.43 \pm 2.64^{\mathrm{a}}$ \\
\hline
\end{tabular}

Control, basal diet; DLM, DL-methionine; MHA-Ca, DL-2-hydroxy-4-methylthio butytric calcium; CME, coated DL-methionine.

${ }^{a b}$ Different letters significantly different $(p<0.05)$.

Table 4. Effects of different methionine sources on egg quality of broiler breeders

\begin{tabular}{|c|c|c|c|c|}
\hline Items & Control & DLM & MHA-Ca & CME \\
\hline Eggshell thickness (mm) & $3.03 \pm 0.02^{b}$ & $3.09 \pm 0.02^{\mathrm{ab}}$ & $3.23 \pm 0.07^{\mathrm{a}}$ & $3.19 \pm 0.10^{a}$ \\
\hline Relative eggshell weight (\%) & $11.33 \pm 0.37^{b}$ & $11.77 \pm 0.35^{\mathrm{ab}}$ & $12.14 \pm 0.22^{\mathrm{a}}$ & $11.88 \pm 0.31^{\mathrm{ab}}$ \\
\hline Eggshell strength (Kgf) & $3.14 \pm 0.40^{b}$ & $3.74 \pm 0.06^{\mathrm{ab}}$ & $4.16 \pm 0.20^{\mathrm{a}}$ & $3.69 \pm 0.11^{\mathrm{ab}}$ \\
\hline Egg shape index & $0.76 \pm 0.01$ & $0.76 \pm 0.01$ & $0.77 \pm 0.01$ & $0.77 \pm 0.02$ \\
\hline Albumen height (mm) & $4.09 \pm 0.68$ & $4.00 \pm 0.49$ & $3.99 \pm 0.29$ & $4.37 \pm 0.44$ \\
\hline Haugh unit & $59.81 \pm 5.82$ & $60.44 \pm 5.03$ & $60.99 \pm 3.04$ & $63.27 \pm 5.44$ \\
\hline
\end{tabular}

Control, basal diet; DLM, DL-methionine; MHA-Ca, DL-2-hydroxy-4-methylthio butytric calcium; CME, coated DL-methionine.

${ }^{a b}$ Different letters significantly different $(p<0.05)$. 
while CME significantly $(\mathrm{p}<0.05)$ increased the eggshell thickness. No difference $(p>0.05)$ was observed among the groups on the egg shape index, albumen height and haugh unit.

\section{Serum physiological and biochemical indices}

The results of different Met sources on serum biochemical profiles are presented in Table 5. Compared with control group, $\mathrm{CME}$ elevated the level of TP $(p<0.05)$ and decreased the concentration of UA significantly $(\mathrm{p}<0.05)$ in serum. And the UA level of serum also significantly $(\mathrm{p}<0.05)$ decreased in DLM, MHA-Ca, and CME groups. The level of serum Ca was higher $(\mathrm{p}<0.05)$ in MHA-Ca supplementation group than that of the other three. No difference ( $p>0.05$ ) was observed among the groups on $\mathrm{P}$ level.

\section{Serum Met metabolites concentration}

Table 6 shows the effects of different Met sources on serum taurine, cysteine and cystanthionine concentrations. Compared with control group, CME supplementation improved the levels of serum taurine, cysteine and cystanthionine significantly $(\mathrm{p}<0.05)$, and DLM and MHA-Ca supplementation significantly $(\mathrm{p}<0.05)$ promoted serum taurine concentration.

\section{DISCUSSION}

Methionine supplementation in basal diets improved the production performance of broiler breeders. Liu et al [12] reported that $0.02 \%$ or $0.04 \%$ DL-Met added into basal diet improved broiler breeders' egg weight. Bunchasak and Silapasorn [13] confirmed that Met intake of $439.93 \mathrm{mg} / \mathrm{hen} / \mathrm{d}$ improved hen-day egg production and egg weight. Our results showed that adding DLM, MHA-Ca, and CME positively affected the laying rate and the F/E of broiler breeders. Moreover, CME significantly improved the laying rate while DLM and MHA-Ca showed a trend of enhancement compared with control group. Meng et al [14] agreed with our studies to a certain extent which they found that breeders' egg weight, laying rate and feed conversion ratio were significantly increased after taking a Met supplemented diet. The explanation could be that Met supplementation enhances protein deposition, thus promote the egg production. Furthermore, Met supplementation may improve production performance through polyamine metabolism pathways [1].

Researches showed that Met plays a critical role on methylation reactions as an essential intermediate and it can be converted into cysteine, which is engaged into synthesizing glutathione and taurine [15]. Our studies also showed Met has a positive role in promoting the reproduction performance. Compared with control group, the fertility rate, hatchability and birth rate in DLM, MHA-Ca, and CME groups were significantly improved. It may because glutathione and cysteine could clear reactive oxygen species (ROS) directly and hence alleviate the deleterious effects of ROS on lipid, protein and DNA structures [16]. And it appears that excessive ROS generated in the embryo development causes negative impacts, which can result in high embryo mortality [17]. Besides, Bunchasak [13] reported that Met could be transferred to fertile eggs, so Met supplementation could improve the antioxidant performance of chick embryo, which would have a positive effect on embryo development. Therefore, Met supplementation might increase the fertility rate, hatching rate and birthrate.

The eggshell thickness, eggshell strength and relative eggshell weight were directly related to eggs' breakage rate. Bunchasak and Silapasorn [13] reported that adding Met in low crude protein diet was of benefit to hens, particularly on eggshell thickness. Data obtained from our study showed that MHA-Ca supplementation significantly improved the eggshell thickness, relative eggshell weight and eggshell strength with. The reason may because $\mathrm{Ca}$ is the first restrictive factor in eggshell formation [18], and the main source of Ca in eggshell are obtained from intestinal absorption and bone Ca mobilization [19]. Thus, the explanation why MHA-Ca promoted the eggshell quality signifi-

Table 5. Effects of different methionine sources on physiological and biochemical indices in serum of broiler breeders

\begin{tabular}{lcccc}
\hline Items & Control & DLM & MHA-Ca & CME \\
\hline Total protein (TP, g/L) & $43.08 \pm 4.93^{\mathrm{b}}$ & $44.28 \pm 2.77^{\mathrm{b}}$ & $45.01 \pm 3.71^{\mathrm{ab}}$ & $50.05 \pm 6.23^{\mathrm{a}}$ \\
Uric acid (UA, mg/L) & $77.44 \pm 13.59^{\mathrm{a}}$ & $64.40 \pm 6.66^{\mathrm{b}}$ & $64.50 \pm 9.07^{\mathrm{b}}$ & $60.88 \pm 6.8^{\mathrm{b}}$ \\
Calcium (Ca, mmol/L) & $2.28 \pm 1.02^{\mathrm{b}}$ & $2.51 \pm 0.13^{\mathrm{ab}}$ & $3.12 \pm 0.99^{\mathrm{a}}$ & $2.64 \pm 0.42^{\mathrm{ab}}$ \\
Phosphorus (P, mmol/L) & $2.05 \pm 0.48$ & $2.09 \pm 0.71$ & $2.45 \pm 0.89$ & $2.38 \pm 0.88$ \\
\hline
\end{tabular}

Control, basal diet; DLM, DL-methionine; MHA-Ca, DL-2-hydroxy-4-methylthio butytric calcium; CME, coated DL-methionine.

${ }^{\mathrm{ab}}$ Different letters significantly different $(p<0.05)$.

Table 6. Effects of different methionine sources on serum methionine metabolites of broiler breeders

\begin{tabular}{lccrr}
\hline Items & Control & DLM & MHA-Ca & CME \\
\hline Taurine $(\mathrm{mg} / \mathrm{L})$ & $36.25 \pm 5.88^{\mathrm{b}}$ & $48.83 \pm 12.30^{\mathrm{a}}$ & $48.89 \pm 6.46^{\mathrm{a}}$ & $49.38 \pm 3.29^{\mathrm{a}}$ \\
Cysteine (mg/L) & $18.34 \pm 4.27^{\mathrm{b}}$ & $19.86 \pm 5.49^{\mathrm{ab}}$ & $20.53 \pm 1.89^{\mathrm{ab}}$ & $24.66 \pm 3.78^{\mathrm{a}}$ \\
Cystanthionine (mg/L) & $0.82 \pm 0.15^{\mathrm{b}}$ & $0.99 \pm 0.35^{\mathrm{ab}}$ & $1.17 \pm 0.16^{\mathrm{ab}}$ & $1.35 \pm 0.33^{\mathrm{a}}$ \\
\hline
\end{tabular}

Control, basal diet; DLM, DL-methionine; MHA-Ca, DL-2-hydroxy-4-methylthio butytric calcium; CME, coated DL-methionine.

${ }^{a b}$ Different letters significantly different $(p<0.05)$. 
cantly may because MHA-Ca provided extra Ca source.

Protein deposition in the body mainly depends on the speed of protein synthesis and catabolism. Serum TP directly reflects the capacity of protein synthesis, and UA is an important indicator of protein catabolism for poultry [20]. It was observed that CME supplementation increased the TP concentration significantly, and DLM, MHA-Ca and CME groups showed a lower serum UA when compared with control group. Results demonstrated that Met could accelerate protein deposition, which was consisted with the laying rate we showed. The explanation maybe that Met could increase the ribosomal capacity ratio (indicator reflecting ribosomal translation efficiency of protein synthesis, up-regulate the mRNA expression levels of protein synthesis-related gene mamalian target of rapamycin ( $m$-TOR), S6 Kinase 1 (S6K1), and eukaryotic initiation factor $4 \mathrm{E}$ (eIF4E), as well as down-regulate protein degradation-related genes ubiquitin and cathepsin B [21].

Methionine affected $\mathrm{Ca}$ and $\mathrm{P}$ metabolism. Richards et al [22] reported that diets with added DLM increased the contents of $\mathrm{Ca}$ and $\mathrm{P}$ in broiler chickens. Our data also showed that DLM, MHA-Ca, and CME supplementation improved the serum $\mathrm{Ca}$ and $\mathrm{P}$ levels compared with control group. And the Ca concentration in MHA-Ca was significantly higher than control group, which was consistent with the results of eggshell quality. The possible reason may due to the extra Ca provided.

Cystathionine was generated by transmethylation in the process of Met metabolism [23], and then cystathionine transsulfuration produced cysteine [24], and cysteine finally transformed into taurine [25], which plays important roles in antioxidant [24]. Therefore, Met supplementation could enhance the antioxidant performance of broiler breeders. The present study showed that DLM, MHA-Ca, and CME supplementation increased serum taurine concentration significantly, which consisted with research conducted by Puchala [26], and also agreed with the fertility rate results in our study.

Coated DL-Met is protected with natural materials that are difficult to be degraded by microorganism and sensitive to $\mathrm{pH}$, which help DL-Met effectively utilized by continuous release. This may explain why CME group had a better performance on laying rate and TP. Coated DL-Met allowed Met to be released slowly in the intestine, thus helped free Met added in feed absorbed synchronously with those metabolized from dietary protein [27].

\section{CONCLUSION}

In conclusion, the present study demonstrated that DLM, MHA$\mathrm{Ca}$, and $\mathrm{CME}$ supplementation could improve the production reproduction performance and egg quality of broiler breeders. Furthermore, CME showed better performance than DLM and MHA-Ca in enhancing production performance and reproduction performance, while MHA-Ca was superior to DLM and CME in terms of the promotion of eggshell quality and serum Ca concentration.

\section{CONFLICT OF INTEREST}

We certify that there is no conflict of interest with any financial organization regarding the material discussed in the manuscript.

\section{ACKNOWLEDGMENTS}

The financial supports provided by the China Agriculture Research System (No: CARS-42-G19, Beijing, China) and Zhejiang Province Key S\&T (project 2013C02010, Hangzhou, China) are gratefully acknowledged.

\section{REFERENCES}

1.Vazquez-Anon M, Gonzalez-Esquerra R, Saleh E. Evidence for 2hydroxy-4 (methylthio) butanoic acid and DL-methionine having different dose responses in growing broilers. Poult Sci 2006;85:140920.

2.Ai Q, Xie X. Effects of replacement of fish meal by soybean meal and supplementation of methionine in fish meal/soybean meal-based diets on growth performance of the southern catfish silurus meridionalis. J World Aquacult Soc 2005;36:498-507.

3.Zhan XA, Li JX, Xu ZR. Effects of methionine and betaine supplementation on growth performance, carcase composition and metabolism of lipids in male broilers. Br Poult Sci 2006;47:576-80.

4.Zhang LB, Guo YM. Effects of liquid DL-2-hydroxy-4-methylthio butanoic acid on growth performance and immune responses in broiler chickens. Poult Sci 2008;87:1370-6.

5.Boebel KP, Baker DH. Efficacy of the calcium salt and free acid forms of methionine hydroxy analog for chicks. Poult Sci 1982;61:1167-75.

6.Chi S, Tan B, Dong X, Yang Q, Liu H. Effects of supplemental coated or crystalline methionine in low-fishmeal diet on the growth performance and body composition of juvenile cobia Rachycentron canadum (Linnaeus). Chinese J Oceanol Limnol 2014;32:1297-306.

7.Martin-Venegas R, Geraert PA, Ferrer R. Conversion of the methionine hydroxy analogue DL-2-hydroxy-(4-methylthio) butanoic acid to sulfur-containing amino acids in the chicken small intestine. Poult Sci 2006;85:1932-8.

8.Sauer N, Emrich K, Piepho HP. Meta-analysis of the relative efficiency of methionine-hydroxy-analogue-free-acid compared with dl-methionine in broilers using nonlinear mixed models. Poult Sci 2008;87: 2023-31.

9.Xie M, Hou SS, Huang W. Effect of excess methionine and methionine hydroxy analogue on growth performance and plasma homocysteine of growing Pekin ducks. Poult Sci 2007;86:1995-9.

10. Van Weerden EJ, Schutte JB, Bertram HL. Comparison of DL-methionine, DL-methionine-Na, DL-methionine hydroxy analogue-Ca, and DL-methionine hydroxy analogue-free acid with layers. Poult Sci 1984;63:1793-99.

11. Benefield BC, Patton RA, Stevenson MJ, Overton TR. Evaluation of rumen-protected methionine sources and period length on performance of lactating dairy cows within Latin squares. J Dairy Sci 2009; 
92:4448-55.

12. Liu Z, Bateman A, Bryant M, Abebe A, Roland D. Estimation of bioavailability of DL-methionine hydroxy analogue relative to DLmethionine in layers with exponential and slope-ratio models. Poult Sci 2004;83:1580-6.

13. Bunchasak C, Silapasorn T. Effects of adding methionine in lowprotein diet on production performance, reproductive organs and chemical liver composition of laying hens under tropical conditions. Int J Poult Sci 2005;4:301-8.

14. Meng GH, Song D, Li LB, et al. Dietary methionine requirement of Jing Brown layer hens from 9 to 17 weeks of age. J Anim Physiol Anim Nutr 2016; doi: 10.1111/jpn.12525.

15. Ekmay RD, Mei SJ, Sakomura NK, Coon CN. The cysteine, total sulfur amino acid, tyrosine, phenylalanine+ tyrosine, and non-essential amino acid maintenance requirements of broiler breeders. Poult Sci 2016;95:1341-7.

16. Willemsen H, Swennen Q, Everaert N. Effects of dietary supplementation of methionine and its hydroxy analog DL-2-hydroxy-4-methylthiobutanoic acid on growth performance, plasma hormone levels, and the redox status of broiler chickens exposed to high temperatures. Poult Sci 2011;90:2311-20.

17. Dong Y, Guo XY, Shi ML. Maternal dietary supplementation with two sources of selenium affects the mortality and the antioxidative status of chick embryo at different developmental periods. Int J Agric Biol 2014;16:629-33.

18. Yenice E, Mizrak C, Gültekin M, Atik Z, Tunca M. Effects of organic and inorganic forms of manganese, zinc, copper, and chromium on bioavailability of these minerals and calcium in late-phase laying hens. Biol Trace Elem Res 2015;167:300-7.

19. Waheed S, Fatima I, Mannan A, Chaudhary MS, Qureshi IH. Trace element concentration in egg-yolk and egg-white of farm and domestic chicken eggs. Int J Environ Anal Chem 1985;21:333-44.

20. Sun Z, Ma Q, Li Z, Ji C. Effect of partial substitution of dietary spraydried porcine plasma or fishmeal with soybean and shrimp protein hydrolysate on growth performance, nutrient digestibility and serum biochemical parameters of weanling piglets. Asian-Australas J Anim Sci 2009;22:1032-7.

21. Dennis MD, Jefferson LS, Kimball SR. Role of p70S6K1-mediated phosphorylation of eIF4B and PDCD4 proteins in the regulation of protein synthesis. J Biol Chem 2012; 287:42890-9.

22. Richards JD, Atwell CA, Vazquez-Anon M, Dibner JJ. Comparative in vitro and in vivo absorption of 2-hydroxy-4 (methylthio) butanoic acid and methionine in the broiler chicken. Poult Sci 2005;84:1397405.

23. Nakamori K, Koyama I, Nakamura T. Effectiveness of taurine in protecting biomembrane against oxidant. Chem Pharm Bull 1990;38: 3116-9.

24. Riedijk MA, Stoll B, Chacko S. Methionine transmethylation and transsulfuration in the piglet gastrointestinal tract. Proc Natl Acad Sci USA 2007;104:3408-13.

25. Thomas EL, Grisham MB, Melton DF. Evidence for a role of taurine in the in vitro oxidative toxicity of neutrophils toward erythrocytes. J Biol Chem 1985;260:3321-9.

26. Puchala R, Pierzynowski SG, Sahlu T. Effects of methionine and hormones on amino acid concentration in the skin of Angora goats. Small Rumin Res 1998;29:93-102.

27. Swennen Q, Geraert PA, Mercier Y. Effects of dietary protein content and 2-hydroxy-4-methylthiobutanoic acid or DL-methionine supplementation on performance and oxidative status of broiler chickens. Br J Nutr 2011;106:1845-54.

28. China Feed Database. Table of feed composition and nutritive value in China: 1998 Edition. China Feed 1999;4:25-31. 